\title{
EXPLORING THE ROLE OF INDIVIDUAL FOOD SECURITY IN THE ASSESSMENT OF POPULATION'S FOOD SAFETY
}

\author{
Magdalena Bobe ${ }^{1}$, Roxana Procopie ${ }^{2}$ and Mihaela Bucur ${ }^{3 *}$ \\ ${ }^{122) 3)}$ The Bucharest University of Economic Studies, Bucharest, Romania.
}

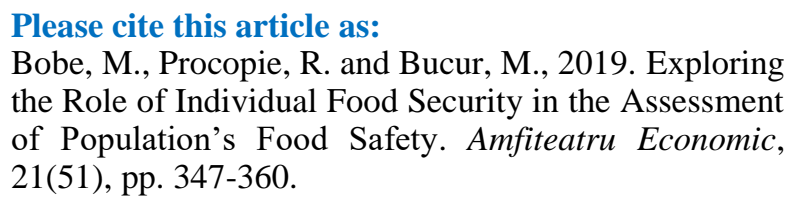

DOI: $10.24818 / \mathrm{EA} / 2019 / 51 / 347$
Article History

Received: 30 December 2018

Revised: 20 February 2019

Accepted: 2 March 2019

\begin{abstract}
Ensuring a sufficient level of food for the population in both quantitative and qualitative terms is a priority for most countries as well as for governmental and non-governmental bodies - be they national, regional or international. The United Nations (UN) stresses the fact that one of the biggest problems the world is facing today is food insecurity. Most people enjoy food security, but the reverse is an unquestionable daily reality for nearly a billion people around the world.

The concept of food security has had different meanings at different times, the definition changing over the years but the fundamental concept behind it remaining the same. When defining food security, we have to adopt a comprehensive approach, taking into account the economical, political, social and cultural factors that shape it, as well as find practical solutions to ensure its continued existence. Thus, resolving the food problem and ensuring food security must start from studying the relationship between consumption needs and the available food resources, rely on anthropometric research methods, and target population segments according to their biological needs.

Starting from the study of the conceptual framework offered by the specialized literature, the present paper aims to clarify and identify the aspects which lie at the basis of studying the food security / insecurity for a population, through exploratory research.

The exploratory research of an individual's food and nutritional security allows for a profound understanding of the concept, the factors that affect it and the interdependence between them, it also ensures a qualitative information gathering process. The results of the study may develop into measures aimed at improving individual food security as part of national food security. This research is done through the method of survey among the students of the Faculty of Business and Tourism, part of the Academy of Economic Studies. The statistical tool used was a questionnaire to identify the nutritional status of the respondents, but also their eating habits. Starting from the necessity of correcting imbalances in the behaviour related to food consumption, our scientific approach can be used to establish solutions for improving food consumption at the individual level, as a dimension of food security, for a segment of the population in Romania.
\end{abstract}

Key words: individual food security, food and nutritional insecurity, nutritional status, nutrition, nutrition education, population.

JEL classification: I 12, L66, Q18, P46.

* Contact author, Mihaela Bucur - mihaela.bucur@ com.ase.ro. 


\section{Introduction}

Among the biggest challenges the world faces today are access to food and the distribution of food already available, along with ensuring a sustainable food production in an ever changing world plagued by acute global crises.

Millions of people simply cannot access the already available food (Young 2012). The planet's population has exceeded 7 billion people and it is estimated to grow to 9.6 billion by 2050 (UN 2013). The pace of growth is much higher than it was in the previous century. Also it is important to note that more and more people enjoy an increase in living standards.

The share of the undernourished population from the total number, in underdeveloped, poor countries sometimes reaches alarming levels due to the scarcity of food in those areas of the globe. Malnutrition and insecurity appear to have increased in almost all sub-regions of Africa as well as in parts of South America, while malnutrition is more stable in Asian regions (FAO, IFAD, UNICEF, WFP and WHO 2018).

At the opposite end of the spectrum, there are developed countries where the proportion of the malnourished population has increased in recent years, largely due to changes in diet, quitting traditional food and adopting a "modern" food diet, rich in refined sugars and fats. This "change" in the diet was determined by changes in society (income growth, city migration, lack of free time).

Food security research has crystallized since the 1970 and has long been centred on studying the issues at international, regional and national level. Initially, the focus was put on food accessibility, availability, and on changes in basic food prices. After 1996, international organizations (FAO, IFAD, UNICEF, WFP and WHO) added to the concept other dimensions such as individual, family or local food security. All of these agree that most important is meeting individual needs and eating high nutrition foods in order to lead an active and healthy life.

The paper highlights these changes from the global level to the individual level, from physical and economic access to basic foods to social access to diverse, nutritious and safe foods, all in order to achieve individual food security. As such, the paper aims at assessing individual food security within a population group, starting from identifying the nutritional status of individuals, analysing anthropometric indicators and observing their eating habits.

The novelty of the work is highlighted by the importance of adopting coherent solutions, and research provides a series of general coordinates that can help set up nutritional policies, starting from the knowledge of the real food behaviour of the population and correcting food imbalances through nutritional education.

\section{Literature review}

International organizations have repeatedly held meetings to try and find solutions and set tangible goals in order to improve food security. The UN has set out the Millennium Development Goals (MDGs), which have been designed as an attempt to support the principles of equality, fairness and human dignity, as well as to eradicate hunger and extreme poverty. 
Severe food insecurity and malnutrition are serious problems affecting many areas of the globe (FAO, IFAD, UNICEF, WFP and WHO, 2018). The number of people affected by famine increased from 815 million in 2016 to 821 million in 2017, which means that 1 out of 9 persons doesn't have the means to feed himself properly (UN, 2018), a pessimistic trend for the future.

In contrast to the phenomenon of malnutrition, there are over 1.3 billion overweight and obese people at a global level (EU Council, 2018). The challenge is thus to reduce this gap by improving access to healthy and nutritious food for a larger proportion of the population.

The inequalities between the rich and the poor are growing, both between regions and within countries. Local government authorities manage public affairs on behalf of and in the interest of local communities they represent (Săraru, 2018). One thing is certain, consolidating a multifunctional rural development can be the measure which starts from providing social welfare through the state, reflected in the anticipated results at a rural level by socioeconomic welfare (Lile, Boghicevici and Stoian, 2018).

Food insecurity and malnutrition affect populations in developed countries due to unhealthy food habits and a lack of education on the topic of healthy nutrition The concept of food security has had different meanings over time and has evolved continuously:

- at the beginning of the 1970s it was defined as "the availability at all times of basic food supplies at a global level in order to maintain a constant expansion of food consumption and compensate for fluctuations in food production and prices" (United Nations, 1975).

- in 1996, the World Food Summit adopted an even more complex definition: "food security at individual, family, national, regional and global level is reached when all people at all times have access to sufficient, safe, nutritious food to maintain a healthy and active life" (FAO, 1996).

- in 2001, the above concept is again completed: "Food security [is] a situation that exists when all people, at all times, have physical, social and economic access to sufficient, safe and nutritious food that meets their dietary needs and food preferences for an active and healthy life" (FAO, 2002).

The most popular definition is the statement made by the Food and Agriculture Organization at the World Food Summit (WFS) in Rome in 1996 that highlights the need for nutritious and safe food, but changes the concept to include not only access to sufficient food, but also access to preferred foods (Schanbacher, 2010). We must, however, understand and be aware of the limitations of this definition and also of how food security interacts with behavioural and factors not related to food. Food security has several obstacles to surmount, mainly linked to international trade, politics, global governance and development plans. Other factors that could affect food security include equity, access to private property, environmental issues and public health services (Young 2012). Global food security is threatened by a range of transversal and often interconnected risks, all with a significant impact (Figure no. 1).

By understanding these risks (for example, their causes, effects and connections), we can find solutions on how to alleviate them and develop the capacity for rapid recovery in order to promote global food security.

The concept of food security is defined by four dimensions: access, availability, stability and use (FAO, IFAD, UNICEF, WFP and WHO, 2018). Access to food is based on two main pillars, physical and economical. Physical access includes mainly the infrastructure necessary for the functionality of the markets. Economic access is influenced by food prices, disposable income and access to social benefits. 


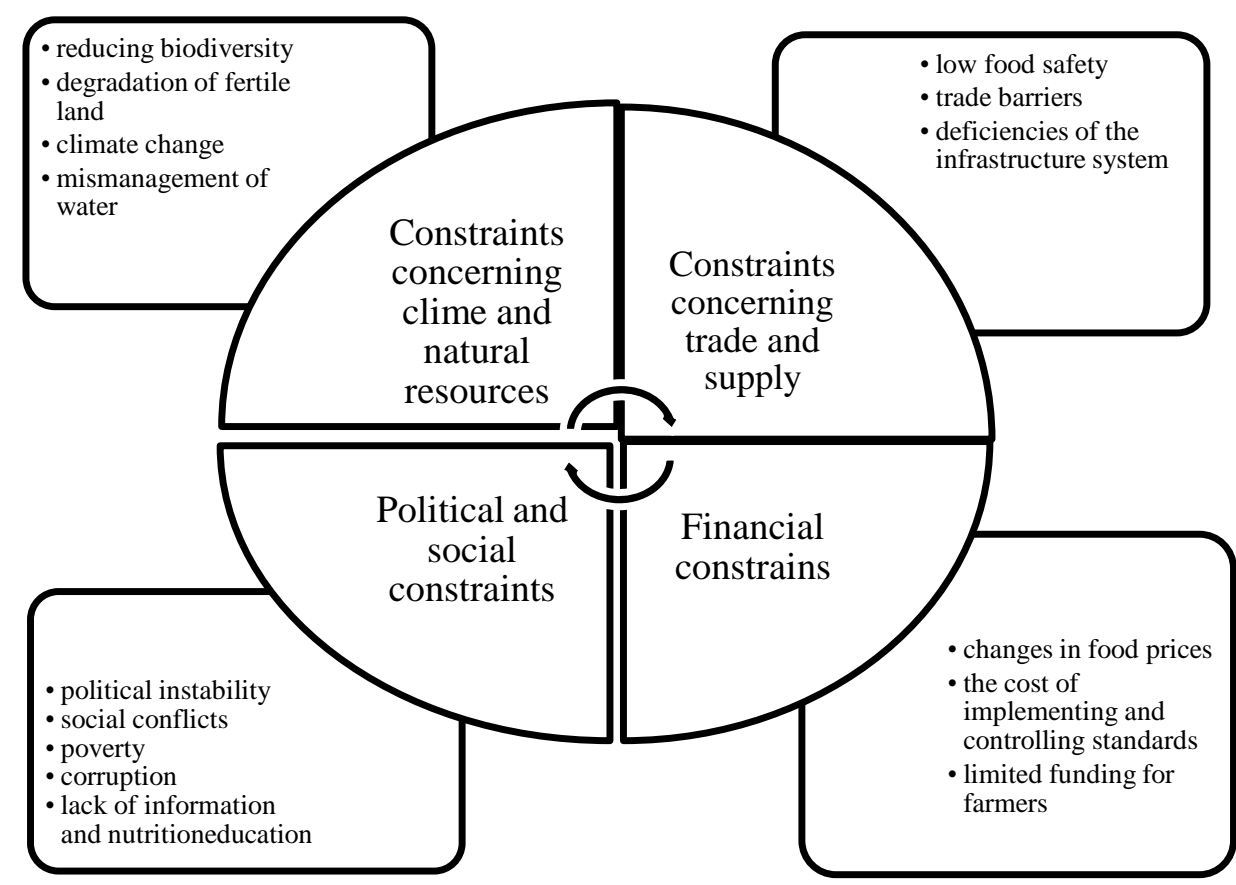

Figure no. 1: Constraints associated with food security and determinant factors

The second dimension is availability. "Providing sufficient food for the population is a necessary but not sufficient condition for food security" (FAO, IFAD, UNICEF, WFP and WHO, 2018).

The third dimension of food security is the stability of the supply and distribution chain and its exposure to various risks; this can be assessed by a set of indicators targeting food imports, price fluctuations for food and raw materials, production size. (FAO, IFAD, UNICEF, WFP and WHO, 2018).

The fourth and last dimension is use and is defined by two factors. The first includes the use of anthropometric indicators to measure how malnutrition affects children's development. The second correlates nutrition with indicators that measure the level of hygiene and health, the quality of food and preparation conditions (FAO, IFAD, UNICEF, WFP and WHO, 2018).

The European Union (EU) has responded to growing challenges related to food security, both in rural and urban areas. The EU policy framework addresses the four dimensions of this concept, broadening their significance (EC, 2010) to:

- improving access to food;

- increasing the availability of food;

- stability by strengthening crisis prevention and crisis management mechanisms;

- improving the use of foods from the nutritional point of view. 
In Romania, according to Project 5. Security and Food Safety in Romania's Development Strategy for the next 20 years 2016-2035 developed by the Romanian Academy, there are several vulnerabilities, including: insufficient domestic agricultural supply (especially meat, vegetables, fruits, sugar and fish); instability of domestic agricultural supply; low incomes, income disparities, inadequate infrastructure (especially in rural areas). All of the factors listed above generate food insecurity; poor quality food consumption, reduced animal protein consumption leading to nutritional risks, high calorie intake due to high consumption of cereals and potatoes; high risk population segments, for example, children in rural areas (Romanian Academy, 2018).

Increasing food security can be achieved by developing nutrition programs and strategies, also developing training programs in nutrition, establishing coordination mechanisms between the agricultural sector and the health, education and social protection sectors, so that future agricultural programs include a nutritional dimension.

\section{Individual food security research among a segment of the population - young students}

\subsection{The context of the research}

Food security from an operational point of view is made up of several segments:

- individual food security (IFS) - represents the possibility of having access to a safe, balanced and adequate diet that ensures a healthy lifestyle; this access must be relatively guaranteed;

- family / household food security - is necessary to ensure the IFS, but is not sufficient, as the available food is not always equally distributed among the family members in accordance to their needs;

- national / regional / global food security - designates the possibilities for different countries to guarantee IFSs without giving up other important national or regional objectives (Figure 2).

Individual food security can be quantified, representing the amount of food needed by an individual, expressed in physical units, and trophins (nutrients), to ensure the physiological balance, to cover the three rations of consumption and to ensure his growth, wellbeing and activity.

The assessment of individual food security must:

- have as a base of analysis the relationship between consumption and resources in order to identify the nutritional status;

- be based on anthropometric research and target individualized groups according to biological requirements;

- identify eating habits. 


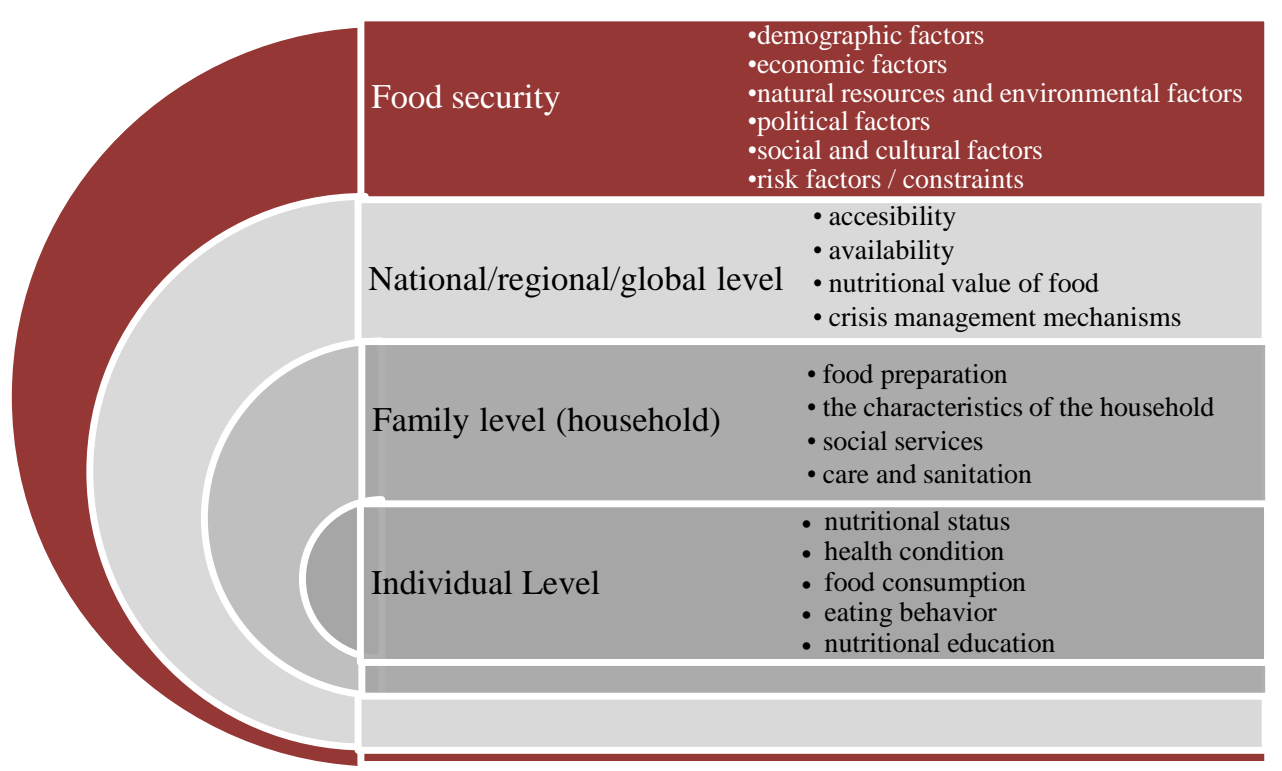

Figure no. 2: Operational food security hypostases

Anthropometry allows for the assessment of the nutritional status of individuals, and anthropometric data is used extensively to analyse the factors that influence the nutritional status of individuals. Anthropometric measurements provide information on the nutritional status of individuals and existing vulnerable groups. They represent the basic component of the nutrition surveillance systems that includes data collection systems to track the evolution of the nutritional level. These systems have developed dramatically in past years.

The most used anthropometric indicators are weight-to-weight ratio or body mass index, weight loss (underweight), weight gain, growth impairment, weight at birth. The benefits of using these indicators are multiple, as they are simple and practical methods of describing the problem, and indirectly provide data on other problems, such as lack of proper access to food and high risks of infection or pollution. It's also a way of verifying the effectiveness of previously implemented programs (WHO, 1995; 2003).

Information obtained through the analysis of the indicators mentioned above can be used at a national level to assess the nutritional level of the entire population in order to identify disadvantaged population groups as well as to identify the reasons for a lower level of nutrition or food insecurity in certain demographic categories.

In contrast to food security, food insecurity occurs when people do not have unhindered access to sufficient amounts of safe and nutritious food, necessary for normal growth and development, as well as for an active and healthy life. (Briones Alonso, Cockx and Swinnen, 2017).

Food insecurity is defined as "a situation of limited or uncertain availability of adequate and safe nutritional foods or the existence of a limited or uncertain capacity to acquire acceptable food in a socially acceptable manner" (Jones, 2013; Nyambayo, 2015). 
Another worrying global food trend is the problem of obesity, especially among young people, which is another facet of food and nutritional insecurity. Statistics show that currently 672 million people are obese and 1.3 billion overweight. The EU Council draws attention to the fact that weight gain and obesity, at a global level coexist with malnutrition and nutrition deficits, one in three people suffering from malnutrition (EU Council, 2018).

Students in Romania represent a vulnerable demographic category because they change their living conditions and lifestyles when they start their university studies: many do not live with their parents, stay in campuses or in leased rooms, some are financially dependent on their parents, others are partly financially independent, have part-time jobs, have no knowledge, time, or the conditions to prepare food, have no concerns about eating correctly (having a regular meal program, diversified diet, knowledge of the biological requirements / nutritional needs of the body). In other words, they are not properly informed on the importance of nutrition.

There are studies at an international level showing concern from various research centres / organizations on how to improve the food security among young students:

- Harvard researchers say that half of American students are affected by food insecurity, which means they often do not have access to quality food. The problem transcends geography and the typology of universities, and researchers cannot yet measure the full consequences of this type of risk, but have linked it with lower graduation rates (Tatter, 2018);

- another extensive research was done in the US, on 3765 college and university students in 12 states (Wang, 2016). The results showed that nearly half of the participants said they had experienced food insecurity, $22 \%$ of the students said that their food insecurity qualifies them as under-nourished and $20 \%$ said they did not eat for a whole day, because they did not have enough money for food. Many students have to find a way to secure their own living expenses while paying for their education, they do not have balanced and adequate nutrition plans (Report, 2016).

The research mentioned above goes on to establish causality between student food insecurity and school abandonment, linking it with the lack of economic access to food because of increased schooling costs. However, this research highlights the unbalanced eating behaviour, developed in the absence of adequate nutritional education.

On the other hand, in Europe, the area of concern is widened and the EU seeks to strengthen global food and nutritional security by eradicating all forms of malnutrition, as stated in the Conclusions of the EU Council (EU Council, 2018). Malnutrition can manifest through one of its three main forms - malnutrition, obesity and micronutrient deficiencies - and it's present in varying degrees in all countries of the region. Often, all these three forms coexist, creating what is called the "triple burden of malnutrition" (FAO, 2018).

This is why our research is focused on tracking the unbalanced eating behaviour of students, a generator of malnutrition and the cause of growing future food insecurity.

Individual food insecurity may be chronic or episodic, severe, moderate or low, and its causes may be multiple and varied: economical, financial, political, social and cultural. In addition, it can stem from: food scarcity, inadequate distribution system, poor infrastructure, lack of purchasing power, poor nutrition education. 


\subsection{Objectives and research methodology}

Starting from the fourth dimension of food security, according to the World Food Summit, Rome 1996, namely use, and from the definition of individual food security (IFS), exploratory research aims to confront - at an individual level - biological requirements met with available food resources and influenced by consumer habits in a college, namely the Faculty of Business and Tourism of the Bucharest Academy of Economic Studies.

From this particular perspective of approaching food security (individual level, balanced nutrition), this exploratory research seeks to clarify and identify key factors in assessing the individual's individual health / insecurity status - as a primary objective, to obtain data that enables the following secondary objectives to be achieved:

- identifying the nutritional status of the respondents by calculating the body mass index for anthropometrical research reasons;

- identifying eating habits and eating behaviour;

- finding solutions to improve eating habits.

Considering that the Faculty of Business and Tourism of the Bucharest Academy of Economic Studies is situated in a more affluent region of the country, Bucharest being the capital of the country and also the city with a poverty rate that is well below the national average and also an average household income above the national average, the research was conducted there and it started from the following premises:

- some respondents do not have a normal healthy weight, according to the calculated individual body mass index, so they do not have a quantitatively and quantitatively balanced food intake in relation to the needs of their bodies;

- the majority of respondents consume nutritionally unbalanced foods;

- a large part of the of the respondents have unhealthy eating habits (no regular meal program, diversified diet, knowledge of the biological requirements / nutritional needs of their bodies), they do not attach importance to the lifestyle-diet-health relationship which in the future will lead to nutritional imbalances;

- no nutritional education.

The research does not follow a predefined model, but it is exclusively adapted to the specifics and needs of the students; moreover, it proves its originality because no investigations on this particular topic have been made in our country.

The present research is based on non-random sampling, it hasn't any statistical relevance, so it can not be considered representative and is carried out following the survey method and using the questionnaire as a tool. The sample consists of 350 students from the Faculty of Business and Tourism of Bucharest Academy of Economic Studies, selected from a total of 1,400 students. They were invited during the period from 1 to 15 November 2018 to participate in this study and asked to respond to 18 questions. The students were approached by the researchers during the courses and asked if they were willing to complete an anonymous questionnaire that would take about 10 minutes. Informal consent was obtained from each participant in the study to ensure that they understood the voluntary nature of the study, the purpose of the study, and the fact that their answers would remain anonymous. 
The questionnaire consists of two parts: questions 1 to 13 aim at assessing the respondents' state of food security / insecurity, while questions 14-18 assess the demographics of students in reference to age, gender, housing status, the average of marks obtained during the former academic year (respectively admissions grades for the 1st year college students). The processing of the data collected was done using the Excel spreadsheet program.

\subsection{Results and discussions}

The characteristics of the sample are presented in Table no. 1.

Table no. 1: The characteristics of the chosen sample

\begin{tabular}{|l|c|c|c|c|c|}
\hline \multirow{2}{*}{ Age } & \multicolumn{2}{|c|}{$18-20$ years } & \multicolumn{2}{c|}{$21-23$ years } \\
\cline { 2 - 5 } & \multicolumn{2}{|c|}{$71 \%$} & \multicolumn{2}{c|}{$29 \%$} \\
\cline { 2 - 5 } Gender & \multicolumn{3}{|c|}{ male } & \multicolumn{2}{c|}{ female } \\
\hline \multirow{2}{*}{ They live with } & \multicolumn{3}{|c|}{ With parents } & In rented areas & In campuses \\
\cline { 2 - 5 } & \multicolumn{3}{|c|}{$46 \%$} & $28 \%$ & $26 \%$ \\
\hline $\begin{array}{l}\text { Average of grades } \\
\text { obtained during the past } \\
\text { academic year exams }\end{array}$ & $5-6$ & $6-7$ & $7-8$ & $8-9$ & $9-10$ \\
\cline { 2 - 6 } & $3 \%$ & $18 \%$ & $32 \%$ & $31 \%$ & $16 \%$ \\
\hline
\end{tabular}

Analysing the structure of the sample we can see that the respondents are between 18 and 23 years old, $71 \%$ amongst them are female and $29 \%$ male; $46 \%$ live with their parents and are in part financially supported by them, $26 \%$ live in university campuses, $28 \%$ live in rented spaces.

The average grade from the past academic year exams (respectively admissions for 1st year college students) fluctuates between 7.01 and 9 so we can conclude that they are students with good academic results.

Respondents are part of an individualized age group divided by gender and recommended nutrition guidelines in our country are used to evaluate the results. These nutrition rules state the energy requirement (in kilocalories or kilojoules) and the amounts of trophins (proteins, lipids, carbohydrates, minerals and vitamins) required for 24 hours to have a normal weight and a proper nutrition intake. The body's requirements for nutrients vary between sexes and between physiological states and between age groups and are also influenced by environmental factors (activity). Therefore, nutrition rules are differentiated by groups of consumers with common physiological characteristics (children, adolescents, women, men) and aim to achieve a balance between what the body metabolizes or loses and what it receives through food. The energy requirement expresses only the quantitative aspect of everyday nutrition, but a healthy body can only be ensured by consuming the necessary nutrients by respecting the required daily quantities and the normal proportions between them in qualitative terms. Nutritional status describes the state of the body, namely the ability to maintain its normal metabolic integrity through nutrition.

The research started firstly by calculating the body mass index calculated individually to identify the nutritional status of the respondents. Starting from the BMI formula = mass $/$ height ${ }^{2}$, respondents identified their weight category. Thus, $75 \%$ of the participants in the 
study fall into the normal weight category (with a BMI between 18.5 and 24.9 ), $15 \%$ fall under the underweight category (with BMI less than 18.5), $8 \%$ in the overweight category (with a BMI between 25.0 and 29.9) and $2 \%$ in the class I obesity (with BMI between 30.0 and 34.9). No respondent falls into the class II obesity category (with BMI between 35.0 and 39.9) and Class III (with BMI greater than 40.0).

This data shows that $25 \%$ of students have a normal body weight according to FAO and WHO recommendations, which is a worrying percentage, because according to these statistics they are threatened by food and nutritional insecurity, either because of excess or food shortage. In addition, fitting into the normoponderal category does not automatically involve nutritional balance and healthy eating. Furthermore, $25 \%$ of respondents said they had consumed an insufficient amount of food over the last week, and $4 \%$ more food than their body needed, experiencing hunger or feeling bloated.

For this reason, the second part of the research was aimed at identifying food consumption habits and eating behavior patterns, as $54 \%$ of respondents no longer live with their parents and do not have adequate means to prepare food or lack the knowledge needed to do so.

Thus, a nutritional imbalance of respondents was observed as a general feature of their behaviour. This is highlighted by the fact that students eat at least once a day nutritionally unbalanced foods: foods containing high amounts of sugar and saturated fat / hydrogenated fats, ultra-processed foods, foods containing insufficient amounts of high-quality protein (sweets: $31,14 \%$, carbonated soft drinks: $19,42 \%$, sausage: $37,14 \%$, industrial pastry products - pretzels, pies, biscuits, waffles, $24,85 \% 85 \%$.

More serious is that many respondents give up cooked food for the main meals and replace them with nutritionally unbalanced foods, consuming sweets 2-3 times a day (18\%), carbonated soft drinks $(16.28 \%)$, pastry products $(7.71 \%)$, fast food $(2.57 \%)$. Very few have three main meals, they do not eat breakfast $(75 \%)$ or lunch $(65 \%)$.

It is alarming that $79.42 \%$ of respondents eat one of the main meals (breakfast $4.85 \%$, lunch $42.85 \%$, dinner $18 \%$ ) or take snacks $(13.71 \%)$ in fast food units on a daily basis. This data sheds a light on the increasing share of fast food and junk food in the daily nutrition.

Another imbalance stems from the lack of diversified protein intake. Thus, $24.28 \%$ of respondents never consume fish, and $25.14 \%$ of respondents never eat vegetables.

The time allotted to eating a main meal on a normal day is too short, as $51 \%$ of respondents allocate only 20 minutes for this, and $23 \%$ only give it 10 minutes. $70 \%$ of respondents do not attach sufficient importance to healthy eating, they do not think about the relationship nutrition-lifestyle, the main reasons being lack of time $(34 \%)$, followed by fatigue and disinterest each with $18 \% 16 \%)$, traffic $(4 \%)$ or family habits $(3 \%)$. With regard to their personal lifestyle improvement goals, $24 \%$ of participants want to adopt a healthier lifestyle, $25 \%$ want to exercise more (the level of physical activity among the respondents, is $58 \%$ mild exercise, $19 \%$ moderate, $17 \%$ sedentary), $18 \%$ want to eat more vegetables and fruits, and $15 \%$ want to gain more muscle mass.

Data analysis shows that students are adopting a diet based on quantity instead of quality, mostly because of poor nutritional education, being both malnourished, overweight, or undernourished. In order to prevent the risk of food insecurity, the population should be made aware of the relationship between diet and health benefits and encouraged to adopt the basic 
principles of balanced eating behaviour, especially the younger generation. (Voinea, Pamfilie and Onete, 2011).

The consequences of an unbalanced eating behaviour are aggravated by a sedentary lifestyle, $17 \%$ of respondents saying they do not do any sort of physical activity, and $58 \%$ are performing light physical activities (1-2 times / week).

The third part of the research aims at finding solutions for improving the use of food at an individual level through information and education programs on nutrition. Nutritional education should be aimed at modifying public communication on nutrition related topics in order to improve the nutritional state for certain population groups.

Nutrition information and education programs can be translated into good eating behaviour guides, which must include some key features in order to be successful:

- have clear and precise objectives;

- state the risk factors associated with inappropriate diet regimes

- identify food behaviours that can be changed, improved, taking into account personal preferences;

- promote simple and practical changes (e.g., number of meals per day at regular intervals, specific amounts of food);

- differentiated based on population categories, taking into account their concerns and lifestyle;

- be easy to receive and understand, contain clear messages;

- be developed for the long run, continue the messages even after healthy eating habits have been adopted to prevent a return to the former behaviour;

- allow program impact assessment studies and regular follow-up to the results, making possible future interventions at appropriate times.

For the category of population targeted by our research, nutrition education should be done in faculties, courses, meetings, work-shops with the involvement of teachers, nutrition specialists, student associations to ensure the proper training of the young generation and ensure positive long-term effects.

\subsection{Limitations and further research directions}

Some limitations of research are worth highlighting. First of all, it should be mentioned that the sample is small (chosen for ease of access), consisting of the students who attended the courses and seminars during the research, and this fact might impact the final results. Secondly, the structure of the sample is unbalanced, with a high percentage of female respondents $(71 \%)$, which may explain to some extent the percentage of underweight people, mainly $15 \%$ (weight loss diets explaining the low quantity of food intake). Thirdly, it was impossible to determine the income allocated to daily food consumption, because the respondents were partially or totally dependent on their parents' allowances, $46 \%$ of respondents still reside with their parents and depending on them. 
We recommend, as a continuation of this research, determining the sphere of food insecurity in university campuses in order to develop short, medium and long-term measures and programs in partnership with non-profit organizations, government agencies and faculties, to help reduce the negative impact an unhealthy diet has on student performance.

\section{Conclusions}

The issue of global food security is far from being solved, both in developing and developed countries. What is certain is that it can not be approached as an isolated event, but only in close connection with other phenomena that characterize the current world economy. Food security is a multidimensional concept that can only be improved by applying well-founded agricultural, food and nutritional policies aimed at restoring food imbalances, starting from the four major causes. Availability and affordability are not sufficient pre-conditions for achieving food security, and the caloric intake of food does not always provide a balanced diet.

At present, malnutrition and over eating coexist. Protein-energy malnutrition is a reality of developed countries and social categories with high incomes. Overeating is favoured by the high disposable income and varied food sources, and is skewed more towards refined food consumption. Reducing the number of overweight people requires a change in their mentality and in their eating behaviour. In order to achieve this, governments and non-governmental institutions have to intervene through nutrition information and education programs for the population.

Knowing individual food behaviour provides a starting point in developing realistic food and nutrition policies that are capable of guaranteeing people's access to adequate food, stable food sources and sufficient supplies, as well as offering solutions on how to improve the diet so as to achieve real food security.

This paper is an attempt to define the populations eating habits, and the individual eating behaviour, starting from identifying the nutritional status of individuals, analysing anthropometric indicators and observing their eating habits. It aims at exploring the role of individual food security in assessing the national degree of food security, and its essential role in ensuring peace, stability and prosperity.

In this context, the evaluation of the nutrition status of students from the Faculty of Business and Tourism of the Bucharest Academy of Economic Studies is relevant given the negative health consequences of an inadequate diet and growing phenomena such as systematic undernutrition / over eating.

This research has reached its main objective, highlighting that food and nutritional insecurity can also occur under conditions of availability and access to food. This result is based on following findings: students' eating habits include unhealthy foods and are often inadequate because they do not eat three main meals a day, they do not allocate enough time to properly eat, they consume nutritionally unbalanced foods, including fast food and junk food, they don't consume food from all the basic groups, and do not give importance to the relationship between lifestyle, nourishment and health. All of these are risk factors that can lead to nutritional imbalances and deterioration of their food security in the future.

People who have unrestricted access to food have the opportunity to improve their individual food security through education, new solutions to the current challenges need to be found. 
These solutions can take the form of state intervention for the benefit of the social categories affected by malnutrition and undernutrition, but they must be complemented by political and economic measures, which will lead to a sustainable solution to this problem. Thus, food security can be improved at both individual, family, local, national and regional levels as well as internationally.

Nutrition education and information programs should promote healthy eating habits and a healthy lifestyle - creating the opportunity for behavioural changes, taking into account individual preferences, lifestyle, cultural values. All of these can in turn lead to an increase in the standard of living.

Communication related to nutrition should be developed taking into account all the development factors from a community. A careful analysis of the effects of such drastic changes in diet is required as it represents an integral part of the cultural heritage of a society.

Addressing the issue of food security from multiple perspectives makes it possible to reveal the causes (also those which have an indirect relationship to eating standards) and to find more solutions than in the past.

\section{References}

Academia Română, 2018. Proiectul 5. Securitate și siguranță alimentară, in Strategia de dezvoltare a României în următorii 20 ani 2016-2035 [online], Available at: <https://acad.ro/bdar/strategiaAR/doc13/StrategiaIII.pdf/> [Accessed 17 November 2018].

Briones Alonso, E., Cockx, L. and Swinnen, J., 2017. Culture and Food Security, in Discussion Paper 398/2017, LICOS Centre for Institutions and Economic Performance, Faculty of Economics And Business, Belgium. Available at: <https://www.researchgate.net/publication/319059417_Culture_and_Food_Security> [Accessed 15 November 2018].

Consiliul UE, 2018. Consolidarea securității alimentare şi nutriționale mondiale - Concluzii ale Consiliului (Bruxelles, 26 noiembrie 2018). [pdf], Available at: <http://data.consilium.europa.eu/doc/document/ST-14554-2018-INIT/ro/pdf> [Accessed 3 December 2018].

Conway, G., 2012. One Billion Hungry. Can We Feed the World?. New York: Cornell University Press.

FAO, 2002. Food security: concepts and measurement, in Trade and Food Security: Conceptualizing the Linkages Expert Consultation Rome, Available at: <http://www.fao.org/3/y4671e/y4671e06.htm> [Accessed 3 December 2018].

FAO, IFAD, UNICEF, WFP and WHO, 2018. The State of Food Security and Nutrition in the World 2018. Building climate resilience for food security and nutrition. [pdf] FAO, Rome. Available at: <http://www.fao.org/3/i9553en/i9553en.pdf> [Accessed 3 December 2018].

FAO, 1996. Rome Declaration on World Food Security and World Food Summit Plan of Action. World Food Summit 13-17 November 1996, Rome.

FAO, 2018. Progress on food security and nutrition stagnates in Europe and Central Asia [online] FAO. Available at: <http://www.fao.org/news/story/en/item/1174262/icode//> [Accessed 27 December 2018]. 
Jones, A.D., Ngure, F.M., Pelto, G. and Young, S.L., 2013. What are we assessing when we measure food security? A compendium and review of current metrics. Adv Nutr, 4(5), pp.481-505.

Lee, R., 2007. Food Security and Food Sovereignty. Centre for Rural Economy Discussion Paper Series. No. 11. University of Newcastle upon Tyne, Newcastle. In: Conway, G. 2012. One Billion Hungry. Can We Feed the World?. New York: Cornell University Press.

Lile, R., Boghicevici, C. and Stoian, C.D., 2018. Role of social professions in the process of sustainable development of rural area. Study case. Juridical Tribune, 8(2), pp.415-424

Maitra, C., 2018. A review of studies examining the link between food insecurity and malnutrition. Technical Paper. [pdf] FAO, Rome. Available at: <http://www.fao.org/3/CA1447EN/ca1447en.pdf> [Accessed 28 December 2018].

Nyambayo, I., 2015. Food Security In Developed Countries (Europe And USA) - Is It Insecurity And Insufficiency Or Hunger And Poverty In Developed Countries?. BAOJ Nutrition, 1(1), pp.1-7.

Report, 2016. Hunger On Campus, The Challenge of Food Insecurity for College Students, National Student Campaign Against Hunger and Homelessness, October 2016, Available at: <https://studentsagainsthunger.org/hunger-on-campus/> Accessed [15 November 2018].

Săraru, C.S., 2018. Considerations about administrative decentralization and local autonomy in Romania. Juridical Tribune, 8(2), pp.596-607.

Schanbacher, W.D., 2010. The Politics of Food. The Global Conflict between Food Security and Food Sovereignty. Santa Barbara: Praeger.

Tatter, G., 2018. Food Insecurity on College Campuses, in Usable Knowledge, November 15, [online] Harvard Graduate School of Education. Available at <https://www.gse.harvard.edu/news/uk/18/11/food-insecurity-college-campuses> [Accessed 29 November 2018].

Voinea, L., Pamfilie, R. and Onete, B., 2011. Foodstuff Consumption Culture among New Generation of Consumers from Romania. Case Study: Students of the Bucharest Academy of Economic Studies. Studia commercialia Bratislavensia, Scientific journal of Faculty of Commerce, University of Economics in Bratislava, 15(3), pp. 438-451.

Wang, L., 2016. Approximately half of college students report food insecurity, study finds. The daily free press, The Independent Student Newspaper at Boston University, 18 october 2016, [online], Available at: <https://dailyfreepress.com/blog/2016/10/12/ approximately-half-of-college-students-report-food-insecurity-study-finds/> [Accessed 29 November 2018].

Young, E.M., 2012. Food and Development. Routledge Perspectives on Development. Routledge: Oxon. 